\title{
Robotic construction: Robotic Fabrication Experiments for the Building Construction Industry
}

\author{
Nuno Pereira da Silva ${ }^{1}$ and Sara Eloy ${ }^{1}$ \\ ${ }^{1}$ Instituto Universitário de Lisboa (ISCTE-IUL), ISTAR-IUL, Lisbon, Portugal. \\ *corresponding author: nuno.a.pereira.silva@gmail.com
}

\begin{abstract}
This paper aims to explore the possibilities that robotic technologies, namely robotic arms and drones, bring to architecture and to the construction sector. The developed research was based in a literature review regarding drones, robotic arms and hybrid automatic construction solutions. The paper starts by presenting a brief resume about the robotic technologies that are presently used, mainly in academic research, to assemble construction elements. We then analyse eight case studies of construction performed with drones and robotic arms in order to explore different approaches to the robotic construction. The advances in robotic construction are visible and growing every year. According to experts, robotic construction will be introduced in the construction industry in a hybrid way by a collaboration between man and machine and not as total substitution of human labour.
\end{abstract}

Keywords: Drones, Robotic Arms, Robotic Construction, Assembly.

\section{Introduction}

This paper intends to identify the potentials that robotic technology can bring to the construction industry. Taking into account the use of robotic elements in other industries such as naval, automotive and computer components, it is questioned here how these technologies could be used for the building construction industry and in what extend it would change it.

Our goal is to explore the possibilities of robotic technology considering the assembly part of construction, both with robotic arms, drones, and hybrid methods were both are combined.

Robotic arms in architecture industry are used mainly to digitally fabricate by subtracting but there are some experiences worldwide using them for the assembly of construction elements. Yet this use is rare and limited to experiments carried out at university level, which have been applied on few occasions in practice. The use of drones in the construction sector has increased considerably in recent years, mainly due to its use for $3 \mathrm{D}$ scanning and photogrammetry. In these cases, drones are used to fly over the intervention areas, carrying cameras or sensors in order to collect data from the building 
sites. The use of drones to assist the assembly of components of the construction has a much smaller advance than the similar one with robotic arms and is limited to a few experiments carried out by universities. In these experiments, researchers seek to explore how this technology can be used to build buildings. Experiments undertaken at ETH Zurich, Stuttgart University and Hongkong University, as "Flight Assembled Architecture", "The Aerial Construction" and "Cyber Physical Macro Material" with drones, "The informed Wall", "The brick Labyrinth" and "Ceramic constellation" with robotic arms and "On the Bri-n-ck" and "ICD/ITKE Research Pavilion 2016/7" with hybrid robotic situations, are good examples of the use of such technologies. (ETHZ, 2017a; Bonwetsch et al., 2017)

This paper is divided into five sections. In section two we identify current robotic construction equipment and briefly systematize their contribution to the automation construction. Section three presents and analyses the more relevant experiments undertaken in the recent years. In section four we discuss the case studies and in the last section we present some conclusions.

\section{Robotic construction}

Regarding robotic construction we will focus this work on Robotic Arms (RA) and drones and how they can be used to assemble parts of a building.

The RA is a robot that functions much like a human arm, being able to function autonomously, or as a part of a more complete robot. The RA is a programmable manipulator, composed of rotational or linear segments that control the precision of their movements (Harris, 2017). On the extreme end of the RA, usually there is a tool which can move, position and manipulate objects. This tool can be a mill to cut, a tube to deposit material, or a claw to grab a brick. In the naval industry, the RA can execute tasks in ship hulls such as electronic components in a faster and more versatile fashion rather than the human hand. Also, in the automobile industry, the RA is used in the assembly line, improving the managing of time consumption and precision (RobotWorx 2019; Harris, 2017).

Drones are Unmanned Aerial Vehicles (UAV). They are manually commanded through remote control, traveling under real-time human control, or programmed using integrated systems of digital control, such as sensors, radars and GPS (Margaret Rouse, 2017). The first UAV, Havilland DH82B from 1935, was piloted by "servo-operated controls", being regularly used as a target aircraft, for realistic anti-aircraft gunnery training. Nowadays, UAVs have been slowly substituting manned aircraft (Pereira da Silva, 2014).

For civilian proposes drones are used for monitoring, mapping, photographing, and even in the movie-making industry. They also serve purposes like material deliveries in hard access zones and in commercial aviation, monitoring of traffic, meteorology and even driving cars. There are three usual dimensions for drones: miniatures, medium-sized (c.15x15cm) and large (c.30 to $40 \mathrm{~cm})$. The large ones can fly outdoors without pre-required conditions and are the more commonly used. The Amazon project 
makes use of the large drones which grant the delivery of packages up to two kilos as in the successful organ delivery test run by Baltimore's St. Agnes Hospital and the University of Maryland (UMD) medical center (Amazon, 2017; Dent, 2019).

\section{Case Studies}

Some of the most technological advanced universities in the world are nowadays developing and experimenting with robotic construction with drones and RA. As said before, the main goal of this paper is to present the current state of the art and the main experiments that have been performed with drones and RA for the assembly of construction elements. In this section of the paper we then analyse eight of those examples. The experiments chosen are divided into three categories, Drone Construction, Robotic Arms Construction and Hybrid construction based on their robotic fabrication technic.

\subsection{Robotic Arm construction}

\subsubsection{Informed Wall Project}

In 2006, the Informed Wall Project was developed in ETH Zurich, led by Fabio Gramazio and Matthias Kohler with the collaboration of post-graduation students. The goal was to build brick walls by using RA to test their architectonic potential. In this experiment students used a robot with six axes, with an intervention area of $3 \times 3 \times 8 \mathrm{~m}$, capable of building architectonical components at a real scale. Another goal of the experiment was to use different materials, processes and shapes in the built process. The construction was designed for no exogenous interferences such as wind, spatial obstacles and human intervention and enabling the RA to reach any point in the tri-dimensional space, executing all the tasks as defined in the Edeffector programme (Bonwetsch et al., 2017). A claw was attached to the RA in order to grab, lift and place traditional bricks in their correct place. A computer script capable of translating the CAD data in coordinates by using the MAYA software was developed. With the combination of the software and the build materials, many wall prototypes were produced, concluding that the RAs can be used in the construction of brick walls with little error. Nevertheless, in order to execute more complex geometric shapes, the team concluded that a bigger investment in software and hardware would be essential, since the materials used - bricks - limit the complexity of the shapes that can be produced. They also concluded that the building process and the reach limitation of the RA have to be considered in the project stage (Bonwetsch et al., 2017).

\subsubsection{The brick Labyrinth}

In 2016, the project "The brick Labyrinth" was developed within the Master of Advanced Studies in Architecture and Digital Fabrication programme resulting of a threemonth group project at ETH Zurich. This was the first large-scale project built in the studio and a unique multi-robotic automated prefabrication in architectural scale. The 
brick Labyrinth is a continuation of the work in robotic control methodology developed by Garmazio and Kholer using a dry-stacked construction. (Piskorec et al., 2018)

The project is divided into three main parts: i) a design and research stage, ii) a computational setup stage and, iii) a fabrication stage. The main goal of this architectural assignment was to design a large-scale labyrinth structure in the RFL Lab (Robotic Fabrication Laboratory) in a space of approximately 100 square meters and a maximum of 12000 dry stack bricks. For doing so the team used one bridge where two ABB robotic arms were mounted (Piskorec et al., 2018)

The design chosen to start the fabrication process consisted of two walls spiralling into each other, measuring 8 by 10 meters and using over 10.000 bricks. The design generated a long winding path resulting into different spatial experiences. (Piskorec et al., 2018)

The Computational setup stage was developed using a Python setup based on COMPAS, an open source framework developed by Philippe Block's research group at ETHZ. The software is split into three main parts, a Computational Design phase, where the final geometry was parametrized according to each wall axis curves to solve transitions problems; a Structural Stability analysis, where the structure mesh data and brick assembly is loaded into COMPAS to create a simple equilibrium analysis and stability by a multiple scenarios analysis; and a Robotic Fabrication Simulation and Online Robot Control, were the fabrication sequence, robot movements and material were modelled and simulated in ABB RobotStudio. (Piskorec et al., 2018)

The last stage was the fabrication process where the result took shape. The used bridge had two telescopic Z-axes and two ABB IRB 4600 2.5 RAs mounted upsidedown, enabling a semi-independent three-dimensional freedom. For the building process it was necessary to develop a brick dispensor, named brick magazine, able to pickup up to eight stacked bricks and deposit them one at the time speeding up the process. The RA places each brick according to the pre-establishes sequence, resulting on the desired structure. (Piskorec et al., 2018, pp. 496-500)

This project introduces strategies to a multi robotic automated brick layering process in large scale, custom made, architectural components in a faster way and without errors to build complex shapes as in the totally digital world. (Piskorec et al., 2018)

\subsubsection{Ceramic constellation / Robotic printed Brick Specials}

In 2017, the "Ceramic constellation pavilion" was developed in the Chinese University of Hong Kong by the work of a group of students and researchers. The project aimed to build a robotic assembled structure made with 3D printed clay bricks each with a unique shape. In this case the 3D printing technic was chosen since it allows mass production of objects, while allowing a great freedom to aesthetically pleasant design alternatives (Lange et al., 2018).

The main goal of this project was to overcome the constraints of the standardized mass production objects allowing for some creative flexibility.

The resulting 3.8 meters tall tower structure is a load-bearing timber pavilion. The pavilion is composed of 2000 terracotta bricks, all uniquely designed, that are dry 
stacked creating a twisted façade (Lange et al. 2018). "The timber framework which supports the pavilion consists of a series of staked horizontal elements, which interlock at each corner with a lap joint modulated to approximate the form of the structure. Each horizontal timber layer substitutes a brick course.” (Lange et al., 2018, p.442)

The fired clay brick, a mainstay of Chinese construction, languished for many years was selected as main material for the structure. (Lange et al., 2018).

For this project around 700 kilograms of raw terra-cotta was used to robotically print several complex shaped and unique bricks, each taking 2 to 3 minutes to print, in total taking over three weeks. After the printing all the bricks were fired at 1025 degrees Celsius (Lange et al., 2018).

This projects consists of "a traditional craft and its inherent material intelligence and how they can be transformed into a flexible and performative building system by the integration of parametric design software and 3D robotic clay printing technology, offering a culturally rooted yet modern material solution for a modernizing China." (Lange, Holohan and Kehne, 2018, p.435)

\subsection{Drone Construction}

\subsubsection{Flight assembly project}

In 2012, Gramazio Koehler's office and the robotic engineer Raffaello D'Andrea, in the "Flight Assembled Architecture" project, programmed a series of drones capable of lifting and assembling thousands of bricks, in the center FRAC in Orleans, a pioneer in assembling modules with drones.

In the stand of four days, a structure with six meters high by three meters in diameter was built, with 1500 polystyrene's parallelepipeds (weighting around 100 grams and measuring 10x30x15 cm) (ETHZ, 2017a). According to Ammar Mirjan, the project intended to verify the possibility of building architectural elements with drones (Hobson, 2015).

To complete this project, many hardware and software had to be developed such as: four drones equipped with specially developed tweezer, each possessing servo-powered pins that, to hold the brick during the flight trajectory, cuts a hole through it; a "blueprint" - a software responsible to inform the drone the precise location and order of each brick; a "foreman" - a software that manages the entire construction process, interconnecting all the software; and a construction team, a subsystem that reads foreman commands, control drones, collision-free zones and trajectories planning and build the structure. (ETHZ, 2017a; Gramazio and Kohler, 2016; Mirjan, 2014).

For Mirjan (2014), drones can be considered as a trustworthy "hand" operating in a three-dimensional space, moving according to the designer pre-established instructions. The used drones were programmed as industrial RAs, with the advantage of allowing greater freedom of movement, allow the construction of higher and more complex structures than those currently built by RAs. The team concluded that, the faster the flight occurred, the less external disturbances (turbulence and collisions) happened resulting in a smaller error margin (ETHZa, 2017; Hobson, 2015; Mirjan, 2014). 


\subsubsection{Aerial Construction Project}

In 2013, The Aerial Construction project was carried out at ETH Zurich in a collaboration between the Institute for Dynamic Systems and Control and ETH Zurich Department of Architecture and Digital Fabrication to investigate and develop a methodology for architectural drone construction.

This experiment aimed at building a rope bridge and was held in the Flying Machine Arena, an interior $10 \times 10 \times 10 \mathrm{~m}$ cubic space equipped with motion capture sensors to constantly geo-locate the drones' position created to carry out experiments with drones. For this experiment two drones equipped with cable dispenser and monitored trolleys to control the tension of the rope throughout the construction process were used. As building material Dyneema nine ropes of $120 \mathrm{~m}$ in length and $4 \mathrm{~mm}$ thickness with high molecular weight, were chosen, for their low weight-resistance ratio being capable of supporting about $1400 \mathrm{~kg}$.

In order to build this architectural element, a supporting structure was needed, to allow different linking elements, such as knots and joints to support the tensile structure, in this case two scaffolds, $7.5 \mathrm{~m}$ apart, where used (Mirjan et al., 2013, page 516; ETHZ, 2017b).

To build the structure, two drones flew around the scaffolding, stretching the Dyneema ropes as if weaving a fabric and creating the basic junction elements in their correct location resulting in a tensed structure. The junction elements were knots (point of intersection of two cables, or between a cable and another object; knots can be fixed or dynamic) and joints (linear element trapped between two structural support points) that were being created according to a parametrized drone' trajectory.

The designed sequence allowed the creation of the desired structure according to the digitally designed shape with the utmost precision:

"Drones lift, place, and connect linear elements to structures in the space, such as pillars or scaffolds, and the tension between the various elements is dynamic and flexible, allowing them to react to the motion of the trajectory sequence of the drones that influence the construction.”(Mirjan et al ., 2013, pp. 514-515)

For this experiment, a specific software was developed. This software had the ability to digitally control the drones, enabling them to communicate between each other and to synchronize their trajectories. In the course of the construction process, structural, static, support points, and dynamic elements where differentiated so that the drones could guide the ropes from one static support to another. (Mirjan et al., 2013)

This experiment proved, for the first time, that small drones can autonomously assemble a full-scale load-bearing structure. Although this project was carried out in the laboratory, its execution presupposes the construction of a bridge of similar characteristics between two slopes of a hillside with difficult access to human labour.

\subsubsection{Cyber Physical Macro Material}

The project Cyber Physical Macro Materials had, as its main objective, to demonstrate an intelligent and dynamic architectural shading system for public spaces capable of autonomously rearrange itself according to human like behavioural patterns. 
In order to build this dynamic and reconfigurable canopy experiment, a specific array of software and modular elements were developed - the Module Structure, a Communication and programming software and a Behaviour system software (Wood et al., 2019).

The Module Structure is constituted of a custom designed "macro scale digital material made of mass producible modular units" (Wood et al., 2019, p.324) made of a Carbon Reinforced Plastic (CFRP) structure, a lightweight carbon fiber filament combined with integrated electronics for communication and sensing operating between modules, alongside a collection of Drones, the 'builders' (Wood et al., 2019). The structure its reconfigurability and the "incorporation of some architectural performance aspects such as transportability, structural capacity, cost, weight, power consumption and aesthetics" was the main goal of the project (Wood et al., 2019).

At the same time, the modules share data between each other through a six pin commercial connector with "a circuit board with a pre-assigned digital ID to process and transmit data to the onboard sensors is mounted in the center of the structure", making possible to the whole system to collect, analyse and provide data to the user (Wood et al., 2019).

For this experiment and regarding the communication and programming part, eight software where specially developed

The Behaviour system controls the modules displacement through the space and is divided into three different patterns, the first is a Responsive behaviour, a system that slowly reconfigures itself so that, despite the sun position, the light and shadow remain consistent through the space. The second is an Interactive Behaviour, a pattern were the user, according to the data received from the units, defines a configuration for the structure, moving modules from less crowded to more crowded zones. And the third is a Learning behaviour, based on old and new data received from the modules, the system will begin to develop unpredicted behaviours and continuously refining the structure (Wood et al., 2019).

The possibility of a structure dynamically reconfigure itself during its use challenges the pre-conceived ideas of robotic digital fabrication for architecture, creating a versatile, autonomously moving canopy that changes according to the sun movement and crowded areas, constantly providing shade and influencing the occupants (Wood et al., 2019).

\subsection{Hybrid construction: Drones as robotic arms}

\subsubsection{On the Bri-n-ck}

In 2009, at the Graduate School of Design in Harvard University, USA, with Ingeborg M. Rocker of Rocker-Lange Architects as main researcher, the Bri-n-ck project was developed. Here researchers used a hybrid of a RA and a terrestrial drone, namely arobotic arm over an autonomous vehicle. 4.100 wooden blocks were used to build two double curvature parallel walls each varying between a straight line and a double curl on the $\mathrm{Z}$ axis (Fairs, 2017).

This project is a synthesis of several previous projects digitally generated and aims to create a real scale wall built only with a self-driven RA. The project presents great 
new challenges in terms of design, new construction techniques, and structural and material constraints (Fairs, 2017).

According to Fairs the habitable space created between the two parallel walls, resulting from the algorithmic pre-defined placement of standard modules turned out aesthetically pleasing resulting from the chosen material, wood, and the scale of construction give good acoustic space capabilities. The scale, the accuracy required, and the large quantity of wooden blocks made it necessary to create a script to enable the robotic construction process.

The project on the Bri-n-ck, reveals a great potential for the construction industry since it allowed to build complex shapes by using simple modular materials. Fairs (2017) believes that the potential of the digital fabrication process in the robotic construction will gradually gain an important and fundamental role in the education of the new generations of architects. This will allow new possibilities for the future of construction by building faster and more complex shapes, reducing human error margin.

\subsubsection{ICD/ITKE Research Pavilion 2016/7.}

In 2017, the ICD (Institute for Computational Design and Construction) in cooperation with the ITKE (Institute of Building Structures and Structural Design) at the University of Stuttgart completed a new robotic construction experiment. The main goal here was to explore the possibility of building real-scale architectural elements, in this case a research pavilion made of glass and carbon fibre-reinforced composites using robotics (one drone and two RAs).

The lightweight and high tensile strength nature of the chosen materials, normally used on other industries such as automotive and aerospace, allowed for a different approach of the digital fabrication process by combining low-payload and long-range machines such as Drones with strong and precise industrial RAs, it enabled the fabrication of a large scale architectural object (RobotWorx, 2019).

In order to build a long and large structure, impossible for the standard industrial fabrication equipment workspace, a collaborative setup between multiple robotic machines communicating between each other was created. This ensured a continuous structure with a seamless fiber laying process, even when passing between machines (Menges \& Knippers, 2019). Achim Menges and Jan Knippers (2019) refer that "this collaborative concept enables a scalable fabrication setup for long span fiber composite construction, which comprised students and researchers within an interdisciplinary team of architects, engineers and biologists."

To accomplished this, two stationary industrial RAs with the necessary precision for the fiber winding work were placed at the extremities of the structure. Simultaneously an autonomous custom-built Drone, with a long range but less precise detailing, transported the fibre between the two robotic arms (ArchDaily, 2019; Menges \& Knippers, 2019).

"Combining the untethered freedom and adaptability of the UAV with the robots, opened up the possibilities for laying fibers on, around or through a structure, creating the potential for material arrangements and structural performance not feasible with the robot or UAV alone." (ArchDaily, 2019) 
The result of this research was a series of pavilions, which investigate computational design integrating engineering and fabrication (Menges \& Knippers, 2019).

\section{Discussion}

In this section we will analyse and compare the case studies presented in section 3 , according to their strengths, weaknesses and final results, in order to identify what can bring more advantages to the construction industries and in what way. To help this comparison we produced Table 1 where we highlight for each case the main achievements, the advantages and the disadvantages, also discussed in this section.

In the RA category, three different projects were selected. The three experiments can be divided into two different categories, ground placed robotic arms and ceiling robotic arms, both presenting different weaknesses and strengths.

The ground placed RAs have a great precision, construction speed, freedom of movements and a varied array of tools reducing errors in the construction of an architectural element. The reduced working area is its biggest weaknesses.

For the ceiling placed RAs, set on moving platforms, all the technological strengths remain while the weakness is reduced by the possibilities of this new location empowered by the moving platform. With such a position the RAs work almost as a drone. Nevertheless, the huge infrastructures needed to integrate the RA on the ceiling increases the overall projects cost. Due to the advantages of this technology many different uses could be prospected within the construction industry. The existence spatial restrains makes it impossible to build big structures, nevertheless it can be used to build small, precise and complex architectural elements.

In the drones' construction category, three experiments were selected for their use of UAV's as building technology to autonomously build the desired structure while using different building material, foam Bricks, Dyneema ropes and custom-made carbon-fiber modules. When comparing the results of each experiment even with different material, all manifested the same strengths and weaknesses caused by the selected building technology. The use of drones allows a greater design freedom and a bigger building space for there are no spatial constraints. Drones are also faster and have a smaller error margin when compared with the handmaid objects. Nevertheless, the limited weight a singular drone can carry is relatively small. Another drawback is that the correction of the unstable external elements makes it crucial to develop new, stronger and more precise drones. Due to the advantages of this technology many different uses could be prospected within the construction industry, it could be used to build in difficult location areas (such as mountain tops, off shore platforms and buildings, under water structures, among others) in patrimonial and historical landmarks requalification, maintenance of big scale structures (such as bridges and wind farms, among other), as well as to build complex shaped buildings.

In the Hybrid Construction experiments category, two experiments were selected for their use of robotic cooperation between drones (terrestrial and aerial) and RAs, with the aim of create larger and more complex architectural structures. The results of the 
reported experiments and their methodology are similar throughout the building processes regardless the different building materials. The analyses of the structures and methodologies behind the projects, show that this building process presents more strengths than weaknesses, since the system uses the stronger features of each technology. The precision and construction speed of the RAs together with the drones' freedom of movements, allows for a larger construction space and therefore the build of bigger structures. As a weakness we can point out the drone role being simply used as a way of transport building materials or RAs from one point to the other. Due to the advantages of this technology, and the simbioses of two efficient technologies, many different uses could be prospected within the construction industry. The cooperation of these two technologies allow for great precision and the construction of bigger building spaces. By reducing the usual spatial restrains of the built equipment these technologies could also be used to build in difficult access location areas in patrimonial and historical landmarks requalification, big scale built sites, and complex shaped buildings, as pointed out before.

After the eight study cases compared and analysed, we can conclude that each of them has different weaknesses and strength that can prove to be useful in different construction scenarios depending on the building specifications, locations, among others.

\begin{tabular}{|c|c|c|c|c|c|c|}
\hline & $\begin{array}{l}\text { Built } \\
\text { object }\end{array}$ & $\begin{array}{l}\text { Robotic } \\
\text { Arms } \\
\text { or } \\
\text { Drones }\end{array}$ & Materials & $\begin{array}{l}\text { Main } \\
\text { achieve- } \\
\text { ment }\end{array}$ & Advantages & $\begin{array}{l}\text { Disad- } \\
\text { vantages }\end{array}$ \\
\hline $\begin{array}{l}\text { Project } 1 \\
\text { Flight } \\
\text { assembly } \\
\text { project } \\
(2012)\end{array}$ & $\begin{array}{l}\text { Complex } \\
\text { geometry } \\
6 \text { meter } \\
\text { tower }\end{array}$ & 4 drones & $\begin{array}{l}1500 \text { pol- } \\
\text { ystyrene's } \\
\text { parallele- } \\
\text { pipeds } \\
\text { Bricks }\end{array}$ & $\begin{array}{l}\text { Complex } \\
\text { shaped build } \\
\text { by autono- } \\
\text { mous drones }\end{array}$ & $\begin{array}{l}\text { Autonomous con- } \\
\text { struction } \\
\text { No spatial con- } \\
\text { straints } \\
\text { Smaller error mar- } \\
\text { gin }\end{array}$ & $\begin{array}{l}\text { Limited } \\
\text { weightVulner- } \\
\text { able to exter- } \\
\text { nal elements }\end{array}$ \\
\hline $\begin{array}{l}\text { Project } 2 \\
\text { Aerial } \\
\text { Construction } \\
\text { Project } \\
(2013)\end{array}$ & $\begin{array}{l}\text { Rope } \\
\text { Bridge }\end{array}$ & 2 drones & $\begin{array}{l}\text { Dyneema } \\
\text { rope }\end{array}$ & $\begin{array}{l}\text { Weight su- } \\
\text { porting lin- } \\
\text { ear element } \\
\text { build by au- } \\
\text { tonomous } \\
\text { drones }\end{array}$ & $\begin{array}{l}\text { Autonomous con- } \\
\text { struction } \\
\text { No spatial con- } \\
\text { straints } \\
\text { Smaller error mar- } \\
\text { gin }\end{array}$ & $\begin{array}{l}\text { Limited } \\
\text { weight } \\
\text { Vulnerable ex- } \\
\text { ternal elements }\end{array}$ \\
\hline $\begin{array}{l}\text { Project } 3 \\
\text { Cyber } \\
\text { Physical } \\
\text { Macro } \\
\text { Material } \\
(2019)\end{array}$ & $\begin{array}{l}\text { Dynamic } \\
\text { shading } \\
\text { system }\end{array}$ & $\begin{array}{l}1-4 \\
\text { drones }\end{array}$ & $\begin{array}{l}\text { Custom } \\
\text { modules }\end{array}$ & $\begin{array}{l}\text { Dynamic } \\
\text { and autono- } \\
\text { mous shad- } \\
\text { ing system }\end{array}$ & $\begin{array}{l}\text { Autonomous con- } \\
\text { struction } \\
\text { No Spatial con- } \\
\text { straints } \\
\text { Smaller error mar- } \\
\text { gin }\end{array}$ & $\begin{array}{l}\text { Limited } \\
\text { weight } \\
\text { Vulnerable to } \\
\text { external ele- } \\
\text { ments }\end{array}$ \\
\hline
\end{tabular}




\begin{tabular}{|c|c|c|c|c|c|c|}
\hline $\begin{array}{l}\text { Project } 4 \\
\text { On the } \\
\text { Bri-n-ck } \\
(2009)\end{array}$ & $\begin{array}{l}\text { Complex } \\
\text { double } \\
\text { curvature } \\
\text { wall }\end{array}$ & $\begin{array}{l}1 \mathrm{RA} \\
1 \text { drone }\end{array}$ & $\begin{array}{l}\text { Wooden } \\
\text { blocks }\end{array}$ & $\begin{array}{l}\text { Hybrid } \\
\text { drone and } \\
\text { robotic arm }\end{array}$ & $\begin{array}{l}\text { Autonomous con- } \\
\text { struction } \\
\text { No Spatial con- } \\
\text { straints Smaller er- } \\
\text { ror margin } \\
\text { Great precision }\end{array}$ & $\begin{array}{l}\text { Limited } \\
\text { weight } \\
\text { Vulnerable to } \\
\text { external ele- } \\
\text { ments }\end{array}$ \\
\hline $\begin{array}{l}\text { Project } 5 \\
\text { ICD/ITKE } \\
\text { Research } \\
\text { Pavilion } \\
\text { (2017) }\end{array}$ & $\begin{array}{l}\text { Research } \\
\text { Pavilion }\end{array}$ & $\begin{array}{l}2 \mathrm{RA} \\
1 \text { drone }\end{array}$ & $\begin{array}{l}\text { Glass and } \\
\text { carbon fi- } \\
\text { bre-rein- } \\
\text { forced } \\
\text { compo- } \\
\text { sites }\end{array}$ & $\begin{array}{l}\text { Hybrid con- } \\
\text { struction so- } \\
\text { lution with } \\
\text { drone and } \\
\text { RA }\end{array}$ & $\begin{array}{l}\text { Autonomous con- } \\
\text { struction } \\
\text { Smaller error mar- } \\
\text { gin } \\
\text { Great precision }\end{array}$ & $\begin{array}{l}\text { Limited } \\
\text { weight } \\
\text { Vulnerable to } \\
\text { external ele- } \\
\text { ments }\end{array}$ \\
\hline $\begin{array}{l}\text { Project } 6 \\
\text { Informed } \\
\text { Wall } \\
\text { Project } \\
\text { (2006) }\end{array}$ & $\begin{array}{l}\text { Complex } \\
\text { shaped } \\
\text { wall }\end{array}$ & $1 \mathrm{RA}$ & Bricks & $\begin{array}{l}\text { Autonomous } \\
\text { RA building }\end{array}$ & $\begin{array}{l}\text { Autonomous con- } \\
\text { struction } \\
\text { Smaller error mar- } \\
\text { gin } \\
\text { Great precision }\end{array}$ & $\begin{array}{l}\text { Small building } \\
\text { area }\end{array}$ \\
\hline $\begin{array}{l}\text { Project } 7 \\
\text { The brick } \\
\text { Labyrinth } \\
(2016)\end{array}$ & $\begin{array}{l}\text { Complex } \\
\text { shaped } \\
\text { labyrinth }\end{array}$ & $2 \mathrm{RA}$ & Bricks & $\begin{array}{l}\text { Autonomous } \\
\text { RA building } \\
\text { RA Ceiling } \\
\text { Position }\end{array}$ & $\begin{array}{l}\text { Autonomous con- } \\
\text { struction } \\
\text { Smaller error mar- } \\
\text { gin } \\
\text { Great precision }\end{array}$ & $\begin{array}{l}\text { Small building } \\
\text { area }\end{array}$ \\
\hline $\begin{array}{l}\text { Project } 8 \\
\text { Ceramic } \\
\text { Constellation } \\
\text { Robotic } \\
\text { printed } \\
\text { Brick } \\
\text { Specials } \\
(2017)\end{array}$ & $\begin{array}{l}\text { High } \\
\text { tower with } \\
3 \mathrm{~m}\end{array}$ & $1 \mathrm{RA}$ & $\begin{array}{l}\text { Custom } \\
\text { Ceramic } \\
\text { Bricks }\end{array}$ & $\begin{array}{l}\text { Autonomous } \\
\text { RA building } \\
\text { Custom } \\
\text { Building ob- } \\
\text { jects }\end{array}$ & $\begin{array}{l}\text { Autonomous con- } \\
\text { struction } \\
\text { No spatial con- } \\
\text { straint Smaller er- } \\
\text { ror margin } \\
\text { Great precision }\end{array}$ & $\begin{array}{l}\text { Small building } \\
\text { area }\end{array}$ \\
\hline
\end{tabular}

Table 1. Table comparing the case studies accordion to the material used, strength and weaknesses of each technology.

\section{Conclusion}

Nowadays, the major robotic construction experiments are developed in Universities and slowly being discussed and integrated into industry. In this paper we focused our research on some of the most recent experiments in academic developed robotic construction held in renowned universities worldwide such as ETHZ, Stuttgart University and Hong Kong University. The main goal was to identify and categorize what has been developed in this field of robotic construction and what are the main achievements and future directions for research.

After the analyses of eight selected cases we concluded that each of them has different weaknesses and strength, similar by type of technology used, that prove to be useful in different construction scenarios depending on the building specifications, locations, 
among others. RAs main target seems to be for the construction of smaller and precise structural and architectural elements. Drones c can be used to build higher and larger building in difficult access locations, for their freedom of movements. Hybrid construction is the one that takes the main advantages of both technologies, uses the strengths while reducing the weaknesses, being the most versatile for the construction industry.

The possibilities that these technologies bring may allow to: i) build complex shapes nimbly and with little to no errors, ii) promote the usage of new materials by the new acquired assembly flexibility; iii) idealize architecture in a new way, enabling the use of free shapes. The RAs and the drones may be used simultaneously, with different tasks, in order to assemblage a building or parts of it, as well as reducing the human error and speeding up the building process.

The three experiments with drones introduced in section 3 were successful, in the construction of tensile structures (through tessellating) and the construction of a brick wall and a dynamic canopy (through deposit). Nowadays, this technology is available but more financial investment and will be necessary to make this process grow and be applied in practice. Both drones and RAs allow a faster construction, with less cost, that enables to explore new shapes and materials, and introduces a new way of thinking that may re-project architecture.

\section{References}

1. Ahlborn,Tom. Industrial robotics in the automotive industry (2015). Industrial Robotics. Retrieved December 10, 2016, from:https://www.bastiansolutions.com/blog/index.php/2015/09/17/industrial-robotics-automotive-industry/\#.WHkgG2NFvJM

2. Amazon (2017). Amazon Prime Air. Amazon.com. Retrieved 31 May 2017, from https://www.amazon.com/Amazon-Prime-Air/b?node=8037720011

3. RobotWarx (2019). What is a robot arm?. Robots.com. Retrieved 17 June 2019, from https://www.robots.com/faq/show/what-is-a-robot-arm

4. Augugliaro, F., D'Andrea, R., Mirjan, A., Gramazio, F., \& M.Kohler. (2013). Architectural fabrication of tensile structures with flying machines. Green Design, Materials And Manufacturing Processes, 513-518.

5. Augugliaro, F., Lupashin, S., Hamer, M., Male,C., Hehn, M., Mueller, M., Willmann, J., Gramazio, F., Kohler, M., D'Andrea, R. (2014) "The Flight Assembled Architecture Installation." IEEE Control Systems Magazine 04, 34 Cooperative Control (2014): 46-64.

6. Bavaria Yachts (2017) Quality: Persuasive power of sailing yachts | BAVARIA YACHTS. Bavariayachts.com. Retrieved 29 May 2017, from https://www.bavariayachts.com/enuk/bavaria/quality/sailing-yachts/

7. Baveria Yachts (2017). YouTube. Retrieved 26 May 2017, from https://www.youtube.com/watch?v=GIciQXXkd4Q\&t=109s

8. Bonwetsch, T., Kobel, D., Gramazio, F., \& Kohler,8 M. (2017). The Informed Wall applying additive digital fabrication techniques on architecture. ACADIA 2017: Synthetic Landscapes Digital Exchange, 491-494.

9. Davidow,William; Malone, Michael. What Happens to Society When Robots Replace Workers? (2014). Harvard Business Review. Retrieved December 10, 2016, from: https://hbr.org/2014/12/what-happens-to- society-when-robots-replace-workers 
10. Dronelli, V. (2017). 8 Heavy Lifting Drones [April 2017 Edition] | Available on Amazon. $\begin{array}{lllll}\text { DronesGlobe.com. } & \text { Retrieved } & 26 & \text { May } & \text { 2017, }\end{array}$ http://www.dronesglobe.com/guide/heavy-lift-drones/

11. Dunn, N. (2012). Digital fabrication in architecture (1st ed.). London: Laurence King.

12. ETHZ (2017). Flying Machine Enabled Construction. Idsc.ethz.ch. Retrieved 2 May 2017, from http://www.idsc.ethz.ch/research-dandrea/research-projects/archive/flying-machineenabled-construction.html

13. ETHZ (2017a). Flying Machine Enabled Construction. Idsc.ethz.ch. Retrieved 2 May 2017, from http://www.idsc.ethz.ch/research-dandrea/research-projects/archive/flying-machine-enabled-construction.html

14. Fionda, Antoinette; Moore, Christopher (2009) The anatomy of the luxury fashion brand. Londres: Palgrave Macmillan UK.

15. Fischer-kowalki, Marina (1998). Society's Metabolism: The intellectual History of Material Flow Analysis. Journal of Industrial Ecology, 61-78.

16. Friedman, Thomas (2000). The Lexus and the Olive Tree. New York: Anchor Books

17. Harris, T. (2017). How Robots Work. HowStuffWorks. Retrieved 12 February 2017, from http://science.howstuffworks.com/robot2.htm

18. Joyner, James. (2014) The US Military's ethics crisis. Retrieved December 2017, from https://www.atlanticcouncil.org/blogs/menasource/the-US-Military's-ethics-crisis

19. Jürgens, Ulrich; Malsch, Thomas; Dohse, Knuth (1993) Breaking from Taylorism: Changing Forms of Work in the Automobile Industry. Inglaterra: Cambridge University Press.

20. Mirjan, A., Gramazio F., Kohler, M., Augugliaro, F. D'Andrea, R (2013) Architectural fabrication of tensile structures with flying machines. Green Design, Materials And Manufacturing Processes, 513-518. Available at http://flyingmachinearena.org/wp-content/publications/2013/augCRC13.pdf

21. Mirjan, A., Augugliaro, F., D'Andrea, R., Gramazio, F., Kohler, M. (2016) "Building a Bridge with Flying Robots." In Robotic Fabrication in Architecture, Art and Design 2016, Dagmar Reinhardt, Rob Saunders, Jane Burry, 34-47. Springer International Publishing, 2016.

22. Patten, Brigg. Robot shoe factory a new trend of the future? (2016). Automation. Retrieved December 20, 2016, from: http://www.automation.com/automation-news/article/robotshoe-factory-a-new-trend-of-the-futurel

23. Pereira da Silva, N. (2014). A ética do militar no século XXI. La Etica Del Soldado Del Siglo XXI, 3(1).

24. Rico, Carolina. Fábrica da Mercedes substitui robôs por pessoas (2016). Noticias ao Minuto. Retrieved Janeiro 10, 2017, from: https://www.noticiasaominuto.com/economia/546316/fabrica-da-mercedes-substitui-robos-por-pessoas

25. Rooks, Brian (1997). Robot welding in Shipbuilding. MCB University Press pp. 413-417

26. Rouse, M. (2017). Drone (unmanned aerial vehicle, UAV) - TechTarget. Retrieved December 2017,from http://internetofthingsagenda.techtarget.com/definition/drone

27. Silva, Nuno Pereira (2016) A construção robotizada em arquitetura. Master Thesis. Instituto Universitário de Lisboa, Lisboa.

28. Wood, D., Yablomina, M., Aflalo, M., Chen, J., Tahanzadeh, B. and Menges, A. (2019). Cyber Physical Macro Material as a UAV [re]Configurable Architectural System. In: J. Willmann, P. Block, M. Hutter, K. Byrne and T. Schork, ed., Robotic Fabrication in Architecture, Art and Design 2018, 1st ed. Zurich: Springer International, pp.320-335.

29. Lange, C., Holohan, D. and Kehne, H. (2018). Ceramic Constellation| Robotically Printed Brick Specials. In: J. Willmann, P. Block, M. Hutter, K. Byrne and T. Schork, ed., Robotic 
Fabrication in Architecture, Art and Design 2018, 1st ed. Zürich: Springer International, pp.435-446.

30. Piskorec, L., Jenny, D., Parascho, S., Mayer, H., Gramazio, F. and Kohler, M. (2018). The Brick Labyrinth. In: J. Willmann, P. Block, M. Hutter, K. Byrne and T. Schork, ed., Robotic Fabrication in Architecture, Art and Design 2018, 1st ed. Zurich: Springer International, pp.490-500. 